\title{
Trematode cercariae infections in freshwater snails of Chitwan district, central Nepal
}

\author{
Ramesh Devkota1*, Prem B Budha ${ }^{2,3}$ and Ranjana Gupta ${ }^{3}$ \\ ${ }^{1}$ Department of Biology, University of New Mexico, Albuquerque, New Mexico, USA \\ ${ }^{2}$ Center for Biological Conservation Nepal, Postbox 1935, Kathmandu, NEPAL \\ ${ }^{3}$ Central Department of Zoology, Tribhuvan University, Kirtipur, Kathmandu, NEPAL \\ * For correspondence, e-mail: devkramesh@hotmail.com
}

\begin{abstract}
Because Nepal has been virtually unexplored with respect to its trematode fauna, we sampled freshwater snails from grazing swamps, lakes, rivers, swamp forests, and temporary ponds in the Chitwan district of central Nepal between July and October 2008. Altogether we screened 1,448 individuals of nine freshwater snail species (Bellamya bengalensis, Gabbia orcula, Gyraulus euphraticus, Indoplanorbis exustus, Lymnaea luteola, Melanoides tuberculata, Pila globosa, Thiara granifera and Thiara lineata) for shedding cercariae. A total of $4.3 \%(\mathrm{~N}=62)$ infected snails were found, distributed among the snail species as follows (B. bengalensis - 1, G. orcula - 11, G. euphraticus - 8, I. exustus - 39, L. luteola - 2 and T. granifera - 1). Collectively, six morphologically distinguishable types of trematode cercariae were found: amphistomes, brevifurcate-apharyngeate (likely mammalian schistosomes), clinostome, gymnocephalus (likely fasciolid), longifurcate-pharyngeate and xiphidiocercaria. I. exustus had the highest prevalence of trematode infection, and harbored all the noted cercarial types except gymnocephalus cercariae. One double infection (xiphidiocercaria and longifurcate-pharyngeate cercaria) was found in this snail. Amphistome cercariae were common in G. euphraticus, G. orcula, and I. exustus. The highest prevalence of infection (38.3\%) was recorded among snails collected from temporary ponds.
\end{abstract}

Key words: digeneans, freshwater snails, paramphistomum, schistosomiasis, trematode cercariae

Digenetic trematodes (also referred to as digeneans or flukes) are common parasites of wild and domestic animals in Nepal (Ghimire 1987, Mahato 1993, Pandey 2001, Devkota 2008, Karki and Manandhar 2008, Lotfy et al. 2010). These parasites all undergo obligatory larval development in snails that are common in the freshwater habitats of the country. Fluke infections can kill or impair the health of their vertebrate hosts, including people, and some digeneans from Nepal are either known to infect people, or are suspected of doing so (Sherchand et al. 1999, Yong et al. 2000). Furthermore, several studies suggest that the distribution and prevalence of trematodes of medical and veterinary significance will be altered and in some cases enhanced by global climate change (Patz et al. 2000, Dobson et al. 2003, Mas-Coma et al. 2009). This potentially includes Fasciola spp., Schistosoma spp. and Paramphistomum spp. in Nepal. However, before we can hope to control these trematodes, or to understand the impact of global climate change on their distribution or abundance in Nepal, we must first have baseline information for what species are present, where and how they are transmitted, and the identity of their snail hosts. Some data are available from other studies of adult digeneans from their definitive hosts and the cercariae in freshwater snails of Nepal (Ghimire 1987, Mahato 1993, Sherchand et al. 1999, Yong et al. 2000, Pandey 2001), but as noted by Devkota (2008), much remains to be learned. In this study, we report on the infection rate of various trematode cercariae in certain freshwater gastropod species of central Nepal. We focused our research on the Chitwan area because trematodes, their host snails and vertebrate hosts that are necessary for propagating the lifecycle of trematodes are abundant in this region.

\section{Methods}

Study area Chitwan district of Nepal, occupying an area of 2,205.9 $\mathrm{km}^{2}$, lies between $27^{\circ} 21^{\prime} 45^{\prime \prime}$ to $27^{\circ} 52^{\prime} 30^{\prime \prime}$ North latitude and $83^{\circ} 54^{\prime} 45^{\prime \prime}$ to $84^{\circ} 48^{\prime} 15^{\prime \prime}$ East longitude. The topography may be described as low hills steeply dissected by numerous permanent and seasonal drainages. The district occupies an economically important position between the Mahabharat Lekh and the Siwalik range, with the most fertile alluvial floodplain land, forest, rivers and lakes in Nepal.

The climate is subtropical monsoon, which is characterized by high temperature and extreme variability in precipitation with hot, humid summers and cool, dry winters. Over $75 \%$ of the annual rainfall is concentrated during the monsoon from June through September, and rainfall from January to April is very low, with an annual average of 2,318 $\mathrm{mm}$.

\section{Collection and identification of freshwater snails}

Freshwater snails were surveyed around four key areas: Jamunapur (N 27 49.005', E 85 23.433'), Tikauli (N 27 38.051', E $84^{\circ} 29.074^{\prime}$ ), Sauraha (N 27 34.386', E 84 29.387') and Shisuwar Bagar (N $27^{\circ} 35.523$ ', E $84^{\circ} 30.011^{\prime}$ ) of Chitwan 
district (Figure 1). Live snails from rivers, grazing swamps, lakes, temporary ponds, and swamp forests were collected with the help of metal sieves or triangular scoops mounted on a long bamboo handle as recommended by Coulibaly and Madsen (1990). The collected snails were kept in dark-colored bottles with wet pieces of papers to keep them alive, and brought to the laboratory for screening within 2 to 3 hours of collection. Infected snail individuals are characterized as "positive" whereas non-infected snails are "negative". The snail species were identified according to Subba Rao (1989), and Nesemann et al. (2007).

\section{Screening of infected snails and identification of cercariae}

Collected snails were rinsed in chlorine-free tap water to remove mud and plants. Each snail was kept in the well of a tissue-culture plate (wellplate) containing clear tap water. The covered well-plates were exposed to window light or strong artificial illumination to stimulate cercarial shedding (Frandsen and Christensen 1984). About an hour later, snails were individually screened under a stereomicroscope for shedding cercariae. Detailed morphology of the cercariae was observed on a slide under a highmagnification compound microscope. Cercariae were photographed using a digital camera (DCM300 CO5B2.0) fitted to a microscope, and they were identified by means of cercarial keys that describes morphological features to identify types of trematode cercariae (Sewell 1922, Combes et al. 1980, Frandsen and Christensen 1984, Schell 1985). Snails that did not shed cercariae in the first hour were monitored for shedding cercariae at half-hour intervals for another 24 hours.

\section{Results}

We collected and examined a total of 1,448 individual freshwater snails of nine different species (Figure 2) belonging to the families Ampullariidae, Bithyniidae, Lymnaeidae, Planorbidae, Thiaridae, and Viviparidae. A total of $4.3 \%$ of sampled individuals belonging to Bellamya bengalensis, Gabia orcula, Gyraulus euphraticus, Indoplanorbis exustus, Lymnaea luteola, and Thiara granifera were found infected with

Figure 2. Freshwater snail species studied for Trematode infections (A. Thiara granifera, B. Melanoides tuberculata, C. Thiara lineata, D. Lymnaea luteola, E. Indoplanorbis exustus, F. Gyraulus euphraticus, G. Pila globosa, H. Bellamya bengalensis and I. Gabbia orcula).

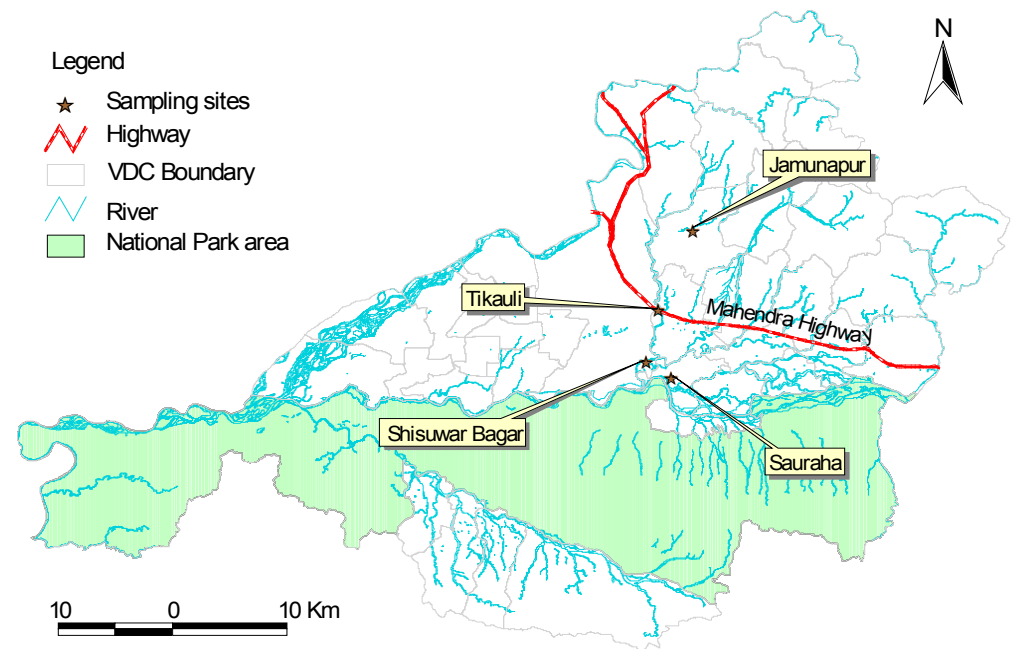

Figure 1. District map of Chitwan showing key sampling locations
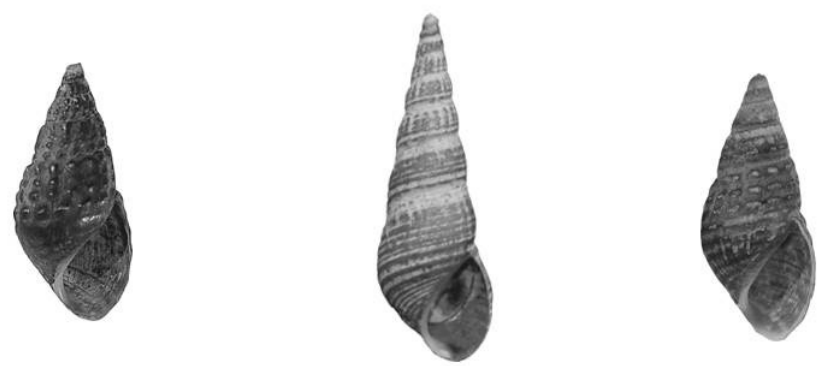

A

B
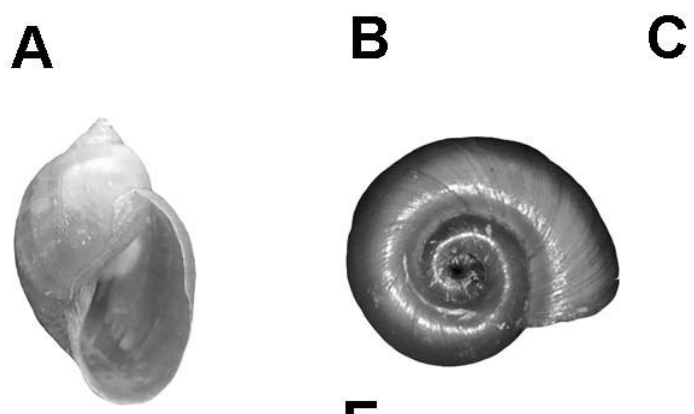

D

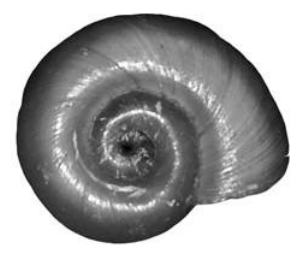

E

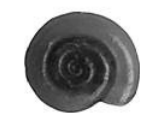

$\mathbf{F}$
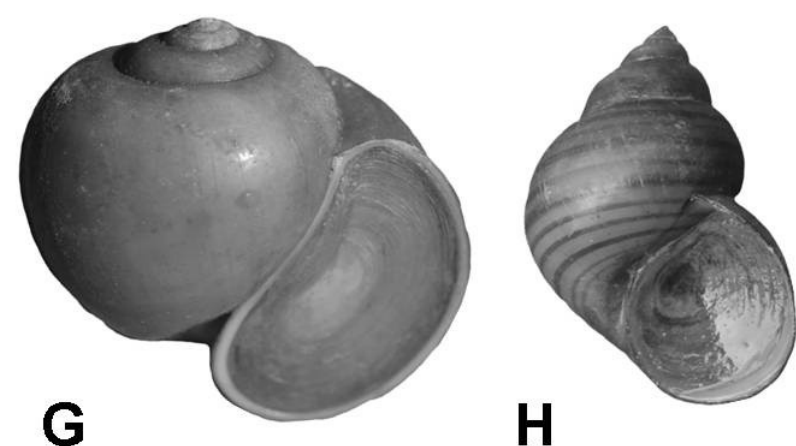

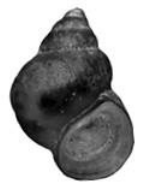

I 
Table 1. Freshwater snail species with the type of trematode cercariae infection in Chitwan district, central Nepal

\begin{tabular}{|c|c|c|c|c|c|c|c|c|c|}
\hline \multirow{2}{*}{$\begin{array}{l}\text { Snail } \\
\text { species }\end{array}$} & \multicolumn{8}{|c|}{ Number of positive cases infected with trematode cercariae } & \multirow{2}{*}{$\begin{array}{l}\text { Infec- } \\
\text { tion } \\
\text { rate } \\
(\%)\end{array}$} \\
\hline & 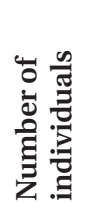 & 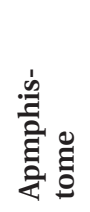 & 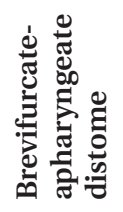 & 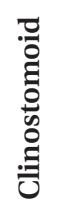 & 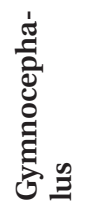 & 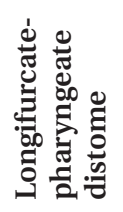 & & 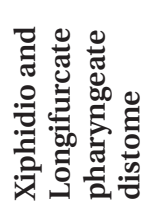 & \\
\hline Bellamya bengalensis & 29 & - & - & 1 & - & - & - & - & 3.4 \\
\hline Gabbia orcula & 440 & 3 & - & - & - & - & 8 & - & 2.5 \\
\hline Gyraulus euphraticus & 230 & 8 & - & - & - & - & - & - & 3.5 \\
\hline Indoplanorbis exustus & 443 & 2 & 4 & 4 & - & 23 & 5 & 1 & 8.8 \\
\hline Lymnaea luteola & 68 & - & - & - & 2 & - & - & - & 2.9 \\
\hline Melanoides tuberculata & 6 & - & - & - & - & - & - & - & - \\
\hline Pila globosa & 39 & - & - & - & - & - & - & - & - \\
\hline Thiara granifera & 130 & - & - & - & - & - & 1 & - & 0.8 \\
\hline T. lineata & 63 & - & - & - & - & - & - & - & - \\
\hline Total snail individuals & 1448 & 13 & 4 & 5 & 2 & 23 & 14 & 1 & 4.3 \\
\hline $\begin{array}{l}\text { Total infection of each type } \\
\text { of cercariae (\%) }\end{array}$ & & 21 & 6.5 & 8 & 3.2 & 37.1 & 22.6 & 1.6 & \\
\hline
\end{tabular}

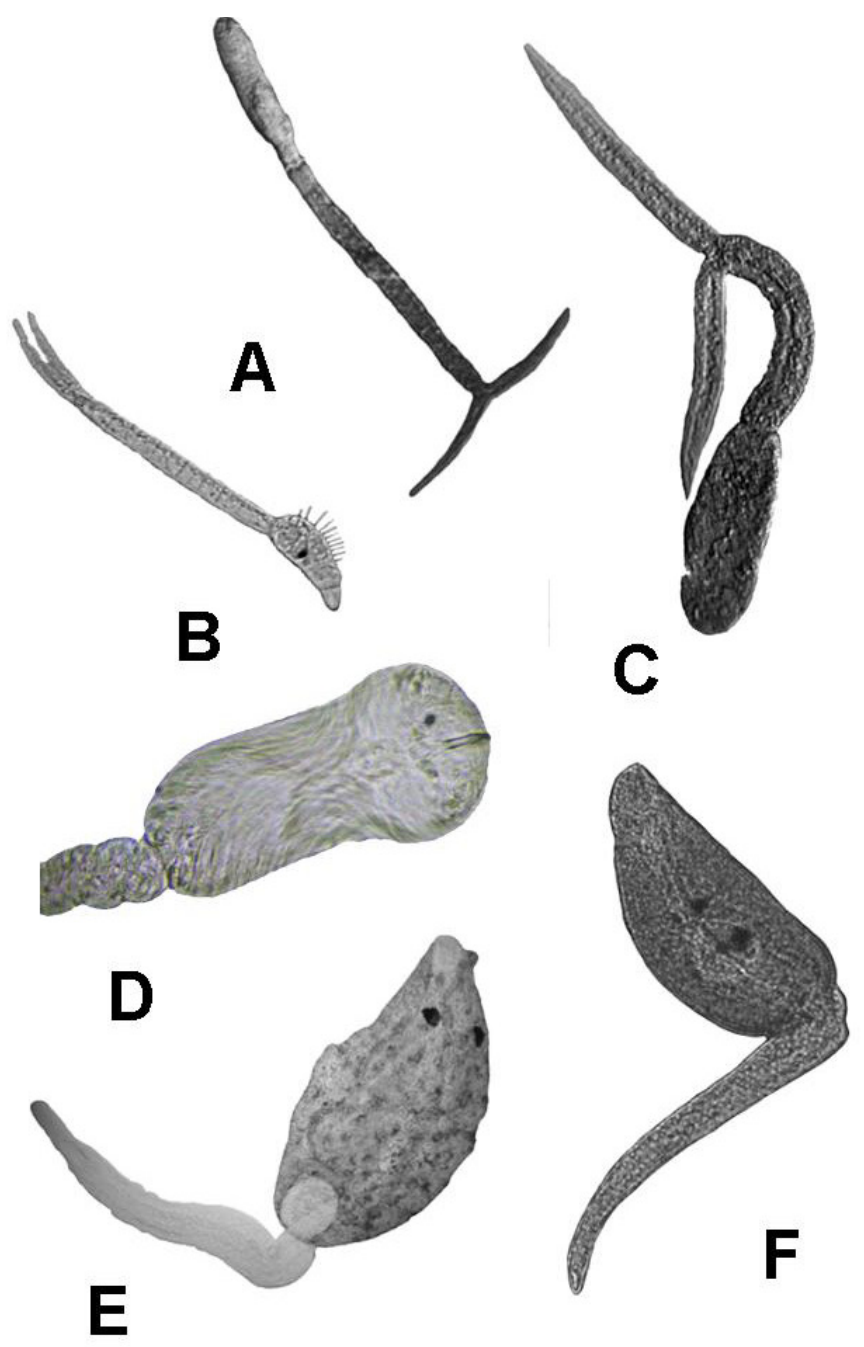

trematode cercariae and no cercarial infection was found in Melanoides tuberculata, Pila globosa, and Thiara lineata. The highest $(8.8 \%)$ prevalence of infection was recorded in I. exustus (Table 1).

Altogether, six morphologically distinguishable cercarial types were recovered: Amphistome cercaria (AC), Brevifurcate-apharyngeate distome (BAD), Clinostomoid cercaria (CC), Gymnocephalus cercaria (GC), Longifurcatepharyngeate distome (LPD) and Xiphidiocercaria (XC) (Figure 3). LPD constituted $37.1 \%$ of positive cases, followed by XC (22.6\%). BAD and LPD were only found in I. exustus while GC was only found in L. luteola. AC and XC showed the most extensive or high host range and were observed in three distinct snail species (see Table 1). Similarly, CC was reported in I. exustus, and B. bengalensis. We found I. exustus infected with most of the forms of trematode cercariae recorded in this study (AC, BAD, CC, LPD, and XC), and we found a double infection (LPD and XC) in one I. exustus individual (Table 1).

The highest prevalence of trematode cercaria was recorded from snails collected in temporary ponds $(38.3 \%)$ followed by lakes (4.7\%), grazing swamps (3.2\%), swamp forests $(1.1 \%)$, and rivers $(0.5 \%)$ (Figure 4$)$.

Figure 3. Trematode cercariae recovered from freshwater snails (A. Brevifurcate-apharyngeate distome,

B. Clinostomoid cercaria, C. Longifurcate-pharyngeate distome, D. Xiphidiocercaria, E. Amphistome cercaria and F. Gymnocephalus cercaria). 


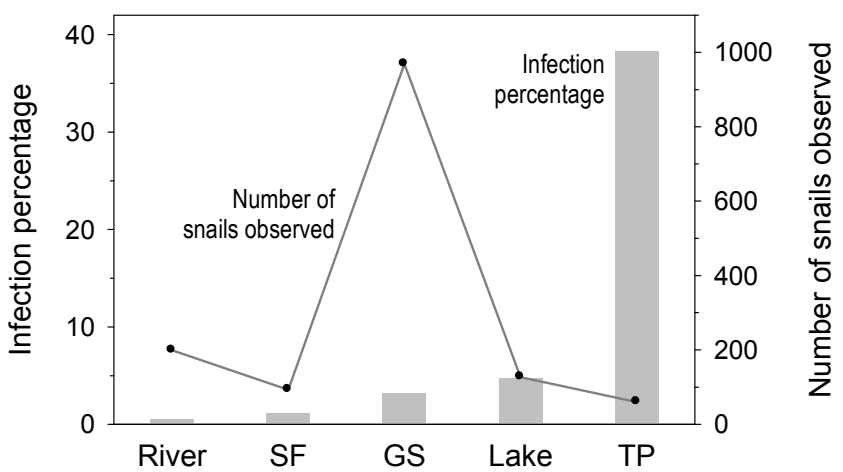

Figure 4. Number of snails and percentage infection in various habitats; $\mathrm{SF}$ = swamp forest, GS = grazing swamp, $\mathrm{TP}=$ temporary ponds.

\section{Discussion}

The present report represents the first study on the diversity of larval trematode parasites (cercariae) of the freshwater snails in Chitwan district of central Nepal. Six morphologically distinguishable types of trematode cercariae were observed in six freshwater snail species with $4.3 \%$ prevalence rate in snail hosts that is higher than the $1.7 \%$ infection rate of Fasciola sp. larvae in Lymnaea sp. from Kavre, Nepal (Pandey 2001), but it is closer to the $3.52 \%$ rate of patent trematode infections reported by Devkota (2008). Such low infection rates in natural snail populations might be the direct consequence of high rates of parasite-induced mortality. Other influential factors may be the difference in snail species observed at different time periods of the year in different studies. Begon et al. (1990) argued that because of host-parasite co-evolution, hosts usually acquire resistance to infection, resulting in low level of observed prevalence. The low prevalence of infection could also be due to low parasite pressure, simply making contact between miracidia and snails a rare occurrence.

In our study, the infection rate in different host snail species ranged from 0.8 to $8.8 \%$. This finding can be compared with the Sewell's findings (1922) of: 6.4-50 percent in G. euphraticus, $5.0-71.1 \%$ in M. tuberculata, and $0.5-44.2 \%$ in I. exustus in Calcutta. Trematode infection in I. exustus was recorded up to $50 \%$ in Wynaad, Madras, India (Sewell 1922). Cercarial infection was more prominent in I. exustus and Lymnaea ovalis than in other snail vectors of the Kaveri River in India (Amanullah and Hameed 1996). One possible explanation of this observation could be the resistance of some snail species to trematode infection, a factor noted by Bayne and Yoshino (1989). Caution must be applied when comparing levels of infection of intermediate host snails from different studies. The present study was based on "patent infection" (Ito 1978). The infection levels of this study might have been significantly higher if the presence of "pre-patent infections" had been studied.

The prevalences of different types of trematode cercariae in different habitats are generally higher than those reported by Pandey et al. (2002) for the rice fields (1.67\%) and streams $(0 \%)$. The highest prevalence rate in temporary ponds in this observation was likely due to the large number of birds perching on trees around the ponds. Many bird species act as final host for strigeoid and clinostomatoid digeneans. Hechinger and Lafferty (2005) demonstrated consistent, positive and significant associations between final host bird communities and trematode communities in intermediate host snail populations. The high prevalence rate in lakes was likely due to the presence of migratory and residential bird species and to several varieties of fishes and reptiles in and around the lakes. The fact that the lowest prevalence rate occurred in rivers may be due to the fast water currents that displace snails or at least keep them from congregating in large numbers and make snail-miracidia contact a rare occurrence. The degree of infection may vary in snails of the same species from one location to another, even though these areas might be apparently similar and geographically proximate to each other. Our obtained results were consistent with those of Sewell (1922).

The six morphologically identified larval trematodes that are recorded from the present study showed similar trends in Zimbabwe, where Chingwena et al. (2002) found eight types of the trematode cercariae. Likewise, the infection rate varies in studies carried out in other countries: six different trematode families in Northern Australia (Hurley et al. 1994), eight trematode species afflicting Batillaria attramentaria in Japan (Miura and Chiba 2007), and five morphologically distinct types of larval trematodes infecting freshwater snails in Zambia (Phiri et al. 2007). Similarly, five morphologically distinguishable types of trematode cercariae were recorded in the Chitwan and Nawalparasi districts of Nepal (Devkota 2008).

The present study revealed that some snail species are apparently capable of acting as primary host to large number of trematode species. I. exustus is capable of acting as a primary host to at least five forms of cercariae; G. orcula to two forms of cercariae, and the remaining species to a single form of cercaria. These findings are similar to those of Devkota (2008), who found I. exustus with four forms (AC, BA, CC, LPC) of cercariae. Based on these observations we anticipated that I. exustus has high potentiality in spreading snail borne diseases viz. schistosomiasis, and amphistomiasis in domestic animals, stregeoid trematodes in aquatic birds and other fish eating vertebrates, and (occasionally) amphistomiasis in humans as reported in different times and different places (Malek and Cheng 1974, Chen et al. 1986, Biswas 1991). By contrast, Sewell (1922) observed M. tuberculata infected with seventeen forms of cercariae, I. exustus with fifteen forms and Amnicola travencorica with twelve forms. Our findings of lower trematode cercarial diversity in this case may be influenced by factors such as study seasons and the distribution and abundance of definitive hosts (Smith 2001). Similarly, Sewell probably looked at far more snails from far more different areas.

As LPD is a common cercaria of strigeoid parasite and can be found in various vertebrate hosts, including birds and mammals, it is not unexpected to find it ranking so high. The "BAD" cercariae are almost certainly mammalian 
schistosomes and therefore noteworthy records for Nepal. Likewise, the gymnocephalous cercariae are those of Fasciola $\mathrm{sp}$. Both of these are potentially very important digeneans of medical and veterinary importance in and around Chitwan.

Concurrent infections with more than one parasite species in a single snail host are comparatively uncommon (Kendall 1964). The present study reported a single individual of I. exustus with double infection. XC and LPD cercariae were observed in the same individual snail. Our finding of a case of double infection can be compared with a true double infection with trematode parasites in two species of snail host, namely M. tuberculata and I. exustus (Sewell 1922). This finding also supports the conclusion that multiple infections should be quite rare. It seems probable that a double infection in mollusks individual is simply accidental and in consequence occurs most commonly in those snails which can act as primary host to the greatest number of trematode species (Sewell 1922). Double infections could be more pathogenic than single species infections resulting in higher mortality (Sousa 1992), leading to under-representation in sampled snails. Other factors proposed by Williams and Esch (1991) and Sousa (1993) are chronological and spatial variations in the profusion of eggs and miracidia of trematode species that limit the likelihood of simultaneous infection by multiple trematode species.

\section{Conclusion}

Freshwater snails distributed in different habitats in Chitwan district were infected with six forms of trematode cercariae. I. exustus was the most common host species for most of the trematode cercariae found in the study period, however the small ponds with livestock mobility were noticed as the richest habitats for snails infected by trematodes. These findings suggest that to control the snail-borne diseases, it is necessary to control the population of I. exustus mainly around temporary ponds prone to cattle grazing. We hope this study will serve to stimulate further work on patent and pre-patent infections of snail hosts; larval behavior and morphology; geographical distribution of trematodes; infections in human beings, livestock and wildlife; and clinical manifestations of trematode infection in Nepal.

\section{Acknowledgements}

The authors are grateful to the Department of National Park and Wildlife Conservation and the Chitwan National Park for providing permission to carry out research in the National Park and Buffer Zone Areas. We are also indebted to Dr. Sara V. Brant for providing the relevant literature and Professor Dr. Eric Sam Loker for providing microscopes and teaching field techniques in sorting and identifying trematode cercariae.

\section{References}

Amanullah B and PS Hameed. 1996. Studies on molluscan diversity in Kaveri river system (Tiruchirappalli, India) with special reference to vector snails of trematode parasites. Current Science 71(6): 473-475

Bayne CJ and TP Yoshino. 1989. Determinants of compatibility in molluscs trematode parasitism. American Zoologist 29: 399-407

Begon ML, L Haeper, and CR Townsend. 1990. Ecology. Oxford, Blackwell Publishers.

Biswas G. 1991. Snail-borne diseases and their role in veterinary public health. In: Snails, Flukes and Man, Zoological Survey of India, Calcutta. 73-78 p

Chen DJ, CZ Fan, Z Yang and HM Yang. 1986. First report of Schistosoma spindale in Yunan Province. Journal of Parasitology and Parasitic Diseases 4: 296

Chingwena G, Mukaratirwa S, Kristensen $\mathrm{T}$ and $\mathrm{M}$ Chimbari. 2002. Larval trematode infections in freshwater snails from the Highveld and Lowveld areas of Zimbabwe. Journal of Helminthology 76(4): 283-293

Combes C, J Albaret, L Arvy, P Bartoli, C Bayssade-dufour, S Deblock, M Durette-desset, C Gabrion, J Jourdane, A Lambert, N Leger, C Maillard, M Matricon, H Nassi, G Prevot, J Richard and A Theron. 1980. Mémoires du muséum national d'histoire naturelle, nouvelle séries, séries A, Zoologie, Tome 115. Paris, Editions du muséum, 38, rue Geoffroy-Saint-Hilaire (Ve). 235 p

Coulibaly G and H Madsen. 1990. Seasonal density fluctuation of intermediate hosts of schistosomes in two streams in Bamako, Mali. Journal of African Zoology 104: 201-212

Devkota R. 2008. Inventory of trematode cercariae infections in freshwater snails in Chitwan and Nawalparasi districts and trematodes infections in domestic elephants of Sauraha [MSc thesis]. Kathmandu: Central Dept Zoology, Tribhuvan University. $41 \mathrm{p}$

Dobson A, S Kutz, M Pascual and R Winfree. 2003. Pathogens and parasites in a changing climate. In L. Hannah and T. Lovejoy (eds.): Climate change and biodiversity: synergistic impacts. Advances in applied biodiversity science 4: 33-38. Center for Applied Biodiversity Science, Conservation International, Washington DC

Frandsen F and NO Christensen. 1984. An introductory guide to the identification of cercariae from African freshwater snails with special reference to cercariae of trematode species of medical and veterinary importance. Acta Tropica 41: 181-202

Ghimire NP. 1987. Incidence of common disease of cattle and buffaloes in Surkhet District. Bulletin of Veterinary Science and Animal Husbandry, Nepal 15: 95-101

Hechinger RF and KD Lafferty. 2005. Host diversity begets parasite diversity: bird final hosts and trematodes in snail intermediate hosts. Proceedings of the Royal Society of Britain 272: 1059-1066

Hurley M, N Hearnden, D Blair and B Kay. 1994. Larval trematodes in freshwater snails at the Ross river reservoir, Northern Australia, with emphasis on Trichobilharzia $\mathrm{sp}(\mathrm{p})$; causative agents of Swimmer's Itch. Australian Journal of Marine and Freshwater Research 45: 563-567

Ito J. 1978. Studies on 6 species of cercariae from Austropepea ollula in Shizuoka Prefecture Japan. Japanese Journal of Parasitology 27: 171-184

Karki, K and P Manandhar. 2008. Incidence of gastrointestinal helminthes in captive elephants in wildlife reserves of Nepal. Articles base, Free Online Articles Directory. Accessed from http://www.articlesbase.com/health-articles/incidenceof-gastrointestinal-helminthes-in-captive-elephants-inwildlife-reserves-of-nepal-335689.html on 4 February, 2010

Kendall SB. 1964. Some factors influencing the development of trematodes in their molluscan hosts. In: Taylor, A.E.R. (Ed.), Host parasite relationships in invertebrate hosts. Oxford, Blackwell Scientific Publications. 51-73 p

Lotfy, W, S Brant, K Ashmaway, R Devkota, G Mkoji, and L Loker. 2010. A molecular approach for identification of paramphistomes from Africa and Asia. Veterinary Parasitology 174(3-4): 234 - 240

Mahato SN. 1993. Epidemiology and Pathogenesis of Fasciolosis in Eastern Nepal. The University of Edinburgh. Ph. D. Thesis

Malek EA and TC Cheng. 1974. Medical and economic malacology. Academic press, New York

Mas-Coma S, MA Valero and MD Bargues. 2009. Climate change effects on trematodiases, with emphasis on zoonotic fascioliasis and schistosomiasis. Veterinary Parasitology 163: 264-280

Miura $\mathrm{O}$ and S Chiba. 2007. Effects of double infection on the shell size and distribution of snail hosts. Parasitology International 56: $19-22$

Nesemann H, S Sharma, G Sharma, SN Khanal, B Pradhan, DN Shah and RD Tachamo. 2007. Aquatic invertebrates of the Ganga 
river system: Volume 1: Mollusca, Annelida, Crustacea (in part). Hasko Nesemann. 263 p

Pandey K. 2001. Prevalence of Fasciolopsis in buffaloes in relation to Fasciola larvae infection in Lymnaea snails in Devbhumi Baluwa VDC of Kavre district [MSc thesis]. Kathmandu: Central Dept Zoology, Tribhuvan University. 58 p

Pandey K, SN Mahato and R Gupta. 2002. Prevalence of Fasciola infection in Lymnaea snails and buffaloes in Devbhumi Baluwa VDC of Kavre district. Journal of Natural History Museum 21: $121-128$

Patz JA, TK Graczyk, N Geller and AY Vittor. 2000. Effects of environmental change on emerging parasitic diseases. International Journal of Parasitology 30: 1395-1405

Phiri A, I Phiri, A Chota and J Monrad. 2007. Trematode infections in freshwater snails and cattle from the Kafue wetlands of Zambia during a period of highest cattle - water contact. Journal of Helminthology 81(1): 85-92

Schell SC. 1985. Handbook of Trematodes of North America North of Mexico. University Press of Idaho. 263 p

Sewell RB. 1922. Cercariae Indica. The Indian Journal of Medical Research X: 1-370
Sherchand JB, H Ohara, S Sherchand and H Matsuda. 1999. The Suspected Existence of Schistosoma mansoni in Dhanusha District, Southern Nepal. Annals of Tropical Medicine and Parasitology 93(3): 273-278

Smith NF. 2001. Spatial heterogeneity in recruitment of larval trematodes to snail intermediate hosts. Oecologia 127: 115-122

Sousa WP. 1992. Interspecific interaction of larval trematode parasites of freshwater and marine snails. American Zoologist 32: 583-592

Sousa WP. 1993. Interspecific antagonism and species coexistence in a diverse guild of larval trematode parasites. Ecological Monographs 63: 103-128

Subba Rao NV. 1989. Hand book of freshwater molluscs of India. Zoological Survey of India, Calcutta. $289 \mathrm{p}$

Willams JA and GW Esch. 1991. Infra and component community dynamics in the Pulmonate snail Helisoma anceps, with special emphasis on the Hemiurid trematode Halipegus occiduals. Journal of Parasitology 77: 246-253

Yong TS, S Sim, J Lee, H Ohrr, MH Kim, and H Kim. 2000. A smallscale survey on the status of intestinal parasite infections in rural villages in Nepal. The Korean Journal of Parasitology 38 (4): $275-277$ 